\title{
Gebruik van 'n ekspertstelsel vir die identifikasie van Lithops
}

\author{
J. Gouws \\ Departement Elektriese en Elektroniese Ingenieurswese, Randse Afrikaanse Universiteit, \\ Posbus 524, Aucklandpark, 2006 \\ jg@ingl.rau.ac.za
}

Ontvang 4 Maart 1999; aanvaar 17 Februarie 2000

\section{UITTREKSEL}

Dit is vir nieplantkundiges dikwels baie moeilik om nabyverwante plante van mekaar te onderskei en te identifiseer: Hierdie artikel bied 'n oorsig van die gebruik van 'n rekenaargesteunde ekspertstelsel vir hierdie doel, spesifiek toegepas op Lithops - 'n groep vetplante met heelwat interspesifieke ooreenkomste, maar ook intraspesifieke verskille. Ontwikkeling van 'n geskikte ekspertstelsel is nie maklik nie, maar as wegspringpunt is 'n stelsel ontwikkel wat gebruik maak van 'n vereenvoudigde databasis en basiese besluitnemingskriteria. Alhoewel akkuraatheid daardeur ingeboet word, is 'n korter reaksietyd in ruil verkry. Die gebruiker verskaf insette t.o.v. die plantprofiel, die voorkoms van die plantgesig en grenslyne, vensters en kanale op die gesig. Die ekspertstelsel beeld dan die gegewe insette op die databasis af, ten einde te bepaal watter plant dit is wat deur die gebruiker se insette beskyf word. Weens die vereenvoudigde aard van die huidige stelsel gee dit tans geen antwoord op sowat 40\% van alle navrae nie, omdat die stelsel in hierdie gevalle nie die gegewe insette met die gestoorde data kan korrelleer nie. In sowat 55\% van die gevalle gee die ekspertstelsel vyf of minder moontlikhede waaruit die gebruiker dan self verder moet kies; en in sowat 5\% van die gevalle word meer as vyf moontlike antwoorde gegee. Alhoewel die stelselwerking tans nog glad nie as baie goed bestempel kan word nie, verteenwoordig dit reeds 'n nuttige hulpmiddel vir die identifikasie van Lithops.

\begin{abstract}
Use of an expert system for identification of Lithops

It is often very difficult for non-botanists to distinguish between and identify closely related plants. This article provides an overview of the use of a computer-based expert system for this purpose, specifically applied to Lithops - a group of succulents that presents mumerous inter-specific resemblances as well as intra-specific differences. The development of a suitable expert system is not an easy task, but as a starting point a prototype expert system, making use of a reduced data set and reduced decision-making criteria, was developed. Although accuracy was thereby lost, a shorter reaction time became possible. The user supplies inputs regarding plant characteristics such as plant profile, appearance of the plant face, and borderlines, windows and channels on the plant face. The expert system maps these inputs onto the database in order to identify the plant described by the user's inputs. Owing to the simplified nature of the current system, about $40 \%$ of all queries go unanswered because the system cannot match the inputs with the stored data. For approximately 55\% of queries, the expert system provides five or less possibilities from which the user himself must then choose one; and for about 5\% of all queries, more than five possible answers are returned. Although the system operation cannot yet be hailed as excellent, it has already proved to be a useful tool for the identification of Lithops.
\end{abstract}

\section{INLEIDING}

Identifikasie van plante in terme van die klassifikasichiërargie (genus, spesie, ens.) is nic altyd 'n maklike taak nie - veral vir nieplantkundiges, wat individuele plante in 'n groot groep van mekaar probeer onderskei. Ten einde akkurate plantidentifikasic te kan doen, verg kundigheid oor al die belangrike kenmerke wat onderlinge onderskeiding moontlik maak. Benewens die vermoë om plantkenmerke akkuraat te kan waarneem en te interpreteer, is die volgende vermoëns ook noodsaaklik vir 'n persoon wat plante wil identifiseer:

- 'n gocie geheue, ten einde plantname en onderskeidende kenmerke te onthou; of

- toegang tot goeic beskrywende literatuur, met illustrasies (foto's en/of lyntekeninge) - sodat plante op grond van vergelykings tussen die illustrasies en die werklike plante geïdentifiseer kan word; of

- toegang tot kundige persone wat met plantidentifikasie kan help.

Hierdie vereistes is nic altyd maklik haalbaar nic, omdat:

- dit moeilik is om groot hoeveelhede plantkenmerke te onthou - veral vir persone wat nie gerecld daarmee werk nic;

- goeie beskrywende literatuur is soms mocilik beskikbaar veral vir minder bekende plantsoorte;
- selfs met goeie literatuur kan dit steeds baie mocilik wees om plantidentifikasic op grond van foto's te doen, omdat aspekte soos dic tyd van die jaar toe die foto geneem is, die beligting wat gebruik is, en dic grocitoestande van die plant wat afgeneem is, kan veroorsaak dat dic plant op dic foto heelwat anders lyk as die natuurlike voorkoms daarvan;

- lyntekeninge kan nie altyd eienskappe soos kleur en fyn detail baic akkuraat aantoon nie; en

- kundige persone is nic altyd byderhand om te help met die identifikasie van plante nie.

Om hierdie probleme te oorbrug, kan tegnologiese hulpıniddels gebruik word om 'n stelsel te ontwikkel, wat:

- 'n groot geheue het, vir maklike opberging en herwinning van groot hoeveelhede data (soos verskillende plantkenmerke en plantname);

- geprogrammeer kan word om vergelykings en afleidings te mak, op grond van die data en vooraf-geprogrammeerde reëls; en

- voortdurend beskikbaar is.

Rekenaargesteunde stelsels wat vir hierdie doel ontwikkel word, staan bekend as ekspertstelsels; en dit verteenwoordig 'n poging om die kennis en redenasievermoë van kundiges op 'n sekere gebied na te boots deur middel van 'n rekenaarstelsel. 
Die genus Lithops' is 'n relatief groot groep plante, met heclwat interspesificke oorecnkomste, asook intraspesificke verskille. Vir icmand met 'n belangstelling in Lithops (hetsy kommersiecl of as stokperdjic) kan dic betroubare identifikasic van hicrdic plante 'n baic mocilike taak word. Om hierdic rede is daar besluit om dic ontwikkeling van 'n rekenaargesteunde identifikasiestelsel vir Lithops te ondersoek. Dic outeur is decglik bewus daarvan dat daar ' $n$ verskeidenheid databasisse vir plantidentifikasic bestaan, ${ }^{2,3} \mathrm{en}$ dat dit hoegenaamd nic 'n nuwe vakgebied is nic. Die doel van hierdie werk was dus nic om baanbrekerswerk op die gebied van plantidentifikasic, of op die gebied van databasisontwikkeling vir hierdic docl te probeer doen nic, maar spesifick om identifikasic van Lithops te probeer vergemaklik. Dit is beslis nic 'n maklike taak nie; en om so 'n stelsel se akkuraatheid op 'n aanvaarbare vlak te kry, sal nog heclwat werk verg. Die doel van hierdic artikel is om die enkele treë wat reeds in hierdic rigting gegec is, kortliks te bespreek.

\section{WAT IS LITHOPS ?}

Lithops is 'n groep vetplante, unick aan suid-westelike $\Lambda$ frika met 'n baie kenmerkende vorm, maar tog met heelwat variasies. Figuur 1 toon lyntekeninge van tipiese sy- en bo-aansigte van Lithops.

Lithops se belangrikste kenmerke is:

- groci laag op die grond - dikwels sonder om veel bokant grondvlak uit te steek;

- is kegelvormig, en het twee vlesige blare met min of meer halfsirkelvormige bo-aansigte - vandaar volksname soos "bokspoortjies", “olifantpootjies" en "becskloutjies";

- die blare droog gewoonlik gedurende die winter op, en maak plek vir twee nuwe blare om uit te groei;

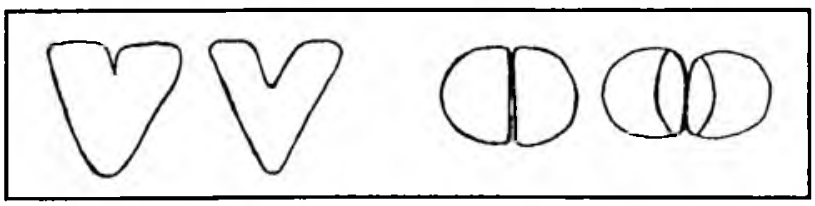

Figuur 1: Tipiese sy-en bo-aansigle van Lithops.
- dic plantgesig (bokant van die twee blare) is normaalweg of plat óf bolrond, maar dit kan ook effens ingeduik voorkom wannecr die plant uitgedroog raak;

- soms vorm mecrvoudige "koppe", oftewel 'n groepie van twee-blarige plantjies aan een penwortel;

- geel of wit blomme kom voor - afhangende van die spesic; en

- die plante is in hul natuurlike omgewing goed gekamoefleer - wat die Engelse volksnaam "flowering stones" verklaar.

Die generiese naam, Lithops, is reeds in 1922 deur dr. N.E. Brown gepubliseer. 'n Eietydse kenner van Lithops, naamlik prof. Desmond Cole, voormalige professor in Afrikatale aan die Universiteit van dic Witwatersrand, het ook baic bygedra tot die bekendmaking van die plante. Hy het in samewerking met sy eggenote, Naureen:

- in dic 1950's begin met navorsing oor Lithops;

- honderde verskillende natuurlike kolonies van Lithops besoek;

- 'n merkwaardige versameling plante vir hulleself opgebou; en

- in 1988 'n uitstekende naslaanbock' oor dic onderwerp gepubliseer. (Ongelukkig is daar slegs 2500 kopicë van hierdic bock gedruk - wat dic beperkte beskikbaarheid van goeic verwysingsliteratuur oor Lithops beklemtoon.)

Plantklassifikasic is nie 'n staticse vakgebied nie. Soos wat nuwe inligting en nuwe insigte deur navorsing bekend raak, is dit soms nodig om plantname en -indelings te verander. Soms word nuwe plante in natuurlike habitat ontdek, en soms word nuwe kultivars gekweck. Sulke ontwikkelinge mak dit nog mociliker vir nieplantkundiges om by te bly met plantname en -klassifikasic. Cole' beskryf 114 Lithops in terme van:

- Spesies, wat gedefinieer word as:

* 'n natuurlike populasic van nabyverwante plante, wat voorkom in een of meer kolonies (gewoonlik geografies geisolecrd en naby aan mekaar geleë);

* plante waar onderlinge inteling binne 'n kolonie plaasvind, maar selde met ander kolonies; en

* plante met unieke kenmerke - wat hulle van ander spesies onderskei.

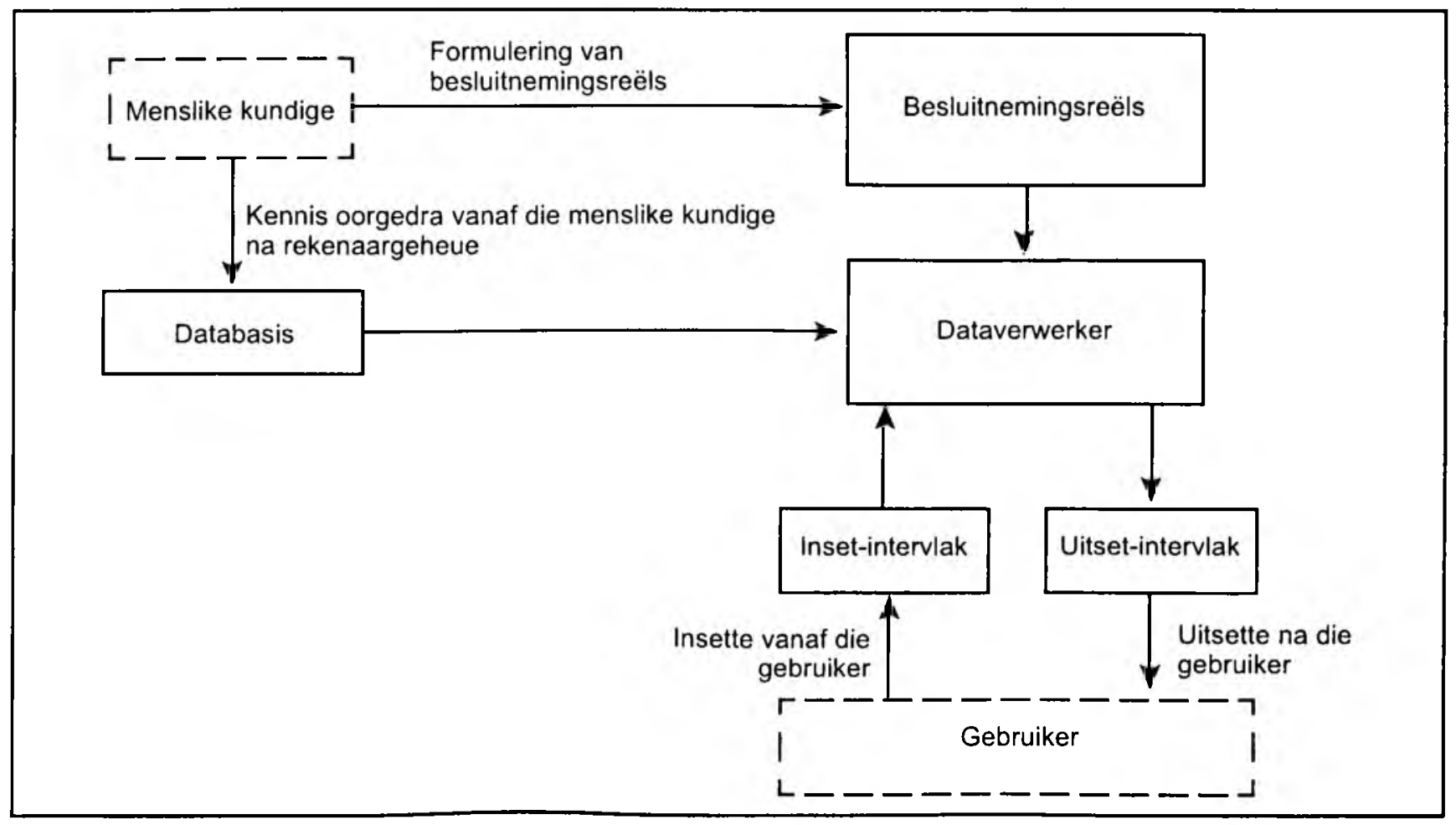

Figuur 2: Funksionele blokdiagram van 'n ekspertstelsel. 
- Subspesies, wat gedefinieer word as:

* plante met dieselfde algemene kenmerke as dic spesie, en

* nabyverwant aan mekaar, maar

* met unicke kenmerke wat hulle van ander subspesies onderskei, en

* wat geografies afsonderlik voorkom.

- Variëteite, wat gedefinieer word as:

* plante met dieselfde algemene kenmerke as die spesic, maar

* wat nader aan mekaar verwant is as dic verwantskap tussen twee subspesies,

* wat onderskei word deur kenmerke soos kleur, grootte, en merke op die plantgesig, en

* wat geografies afsonderlik kan wees, maar nic noodwendig nic.

- Kultivars, wat gedefinicer word as:

* gekweckte variëtcitc, wat normaalweg nic in dic natuur voorkom nic, maar wat ontstaan as gevolg van kunsmatige kwcking, en

* wat gevolglik byvoorbecld albinisme vertoon in die blare of in die blomme (wit blomme in plaas van normaalweg gecl blomme vir 'n spesificke plant).

Met al hierdie opsies is die akkurate identifikasie van 'n gegewe Lithops-plant 'n omvangryke taak - selfs vir dic warc kundiges op dic gebied. 'n Rekenaargesteunde ckspertstelsel het egter die potensiaal om hierdic taak aansienlik te vergemaklik - mits die aanvoorwerk daarvoor behoorlik gedoen is.

\section{REKENAARGEBASEERDE EKSPERTSTELSELS}

'n Rekenaargebasecrde ckspertstelsel ${ }^{4.5 .6 .7}$ is 'n rekenaarstelsel wat geprogrammeer is om data te verwerk en om afleidings te mak op grond van insette wat daaraan verskaf word - soortgclyk as wat 'n menslike kundige onder dieselfde omstandighede, en met dieselfde inligting beskikbaar, sou doen. Verskeie programstrukture ${ }^{2}$ en -tale bestaan vir hierdic doel. In breë trekke kan 'n rekenaargebaseerde ekspertstelsel voorgestel word soos in figuur 2 .

\subsection{Databasis}

Dic doel van die ekspertstelseldatabasis is om sovecl as moontlik van dic beskikbarc kennis oor die betrokkc onderwerp, op ' $n$ geordende wyse in rekenaargeheue op te berg. Die inligting word verkry vanaf een of meer menslike kundiges op die gebied hetsy deur persoonlike kommunikasie, of vanuit literatuur wat deur dié kundiges saamgestel is. 'n Rekenaarprogrammeerder vertaal dan die beskikbare inligting na 'n formaat wat aanpas by die spesifieke tipe databasis wat gebruik word. Hicrdic vertaling moct op so ' $n$ wyse plaasvind dat die inligting maklik bruikbaar is vir dic ekspertstelsel.

\subsection{Besluitnemingsreëls}

Die ekspertstelsel kan alleen besluite neem op grond van voorskrifte wat ook deur menslike kundiges voorsien word. Hicrdie reëls is 'n formulcring van dic manier waarop dic kundiges besluite sou neem, op grond van die beskikbare inligting. Dic formaat waarin die reëls in dic rekenaar geprogrammeer word hang, hoofsaaklik af van dic programtaal wat gcbruik word.

\subsection{Insette}

Benewens die cenmalige insette tot die ekspertstelsel in die vorm van inligting in die databasis en die besluitnemingsreëls, benodig die ekspertstelsel ook ander insette vanaf 'n gebruiker. Hierdic insette word tipies gegee as antwoorde op vrae wat op 'n sistematiese wyse deur die rekenaar gestel word. Dic antwoorde wat verskaf word, bepaal die rigting van verdere vrac. Tipies behoort die vrac gestel te word in volgorde van dalende diskriminasic - mla.w. elke vraag moet telkens dic grootste moontlike aantal nierclevante opsies uitskakel. Vir dic identifikasie van Lithops kan dic eerste vraag (met dic moontlike antwoorde waaruit gekies kan word) bv. wees: "Wat is dic klcur van die blomme? (wit / geel / onbekend)". Indien dic klcur van die spesificke plant se blomme bekend is, skakel hierdie antwoord onmiddellik 'n groot klomp nierelevante plante uit wat al 'n groot stap is in dic rigting van 'n uiteindelike unicke antwoord.

\subsection{Dataverwerker}

Dic dataverwerker gebruik die besluitnemingsreëls, die databasis, en die gebruiker se insette ten einde afleidings te maak, en ten einde op verdere vrae te besluit. Die dataverwerker kombineer losstaande brokkies inligting tot 'n geheel. 'n Voorbeeld van vrae (met net ja of nec as moontlike antwoorde) wat gevra kan word ten cinde inligting in te samel wat deur 'n dataverwerkingsalgoritme tot 'n geheelbeeld gekombineer kan word ten einde te besluit of ' $n$ plant tot die Lithops-genus behoort of nic, is:

1. Is dit 'n vetplant?

2. Bestaan dic gesig van die plant uit twee halfsirkelvormige lobbe?

3. Is die plantdeursnee minder as sowat $4 \mathrm{~cm}$ ?

Indien dic antwoord op cnige van hierdic vrac nee is, is dic plant nic 'n Lithops nic, en kan dic proses dadelik gestop word; andersins is dit heel moontlik een van die Lithops-spesies; en kan verdere vrac gebruik word om die sckerheid daaroor te verhoog.

\subsection{Uitsette}

Die uiteindelike doel van 'n ekspertstelsel vir die identifikasic van Lithops is om 'n spesifieke plant een-eenduidig te identifiseer, op grond van insette wat deur dic gebruiker verskaf is n.a.v. 'n reeks vrac wat deur dic rekenaar gestel is. Dic akkuraatheid van dic uitset hang hoofsaaklik af van dic akkuraatheid en omvang van:

- inligting wat in dic databasis gestoor is;

- vrac wat in dic ekspertstelsel ingeprogrammeer is;

- antwoorde wat deur die gebruiker verskaf word; en

- besluitnemingsreëls wat in dic ekspertstelsel ingeprogrammeer is.

\subsection{Voorwaartse en truwaartse aanwending}

'n Ekspertstelsel kan voorwaarts of truwaarts aangewend word. Met dic voorwaartse metode verskaf die gebruiker individuele brokkies inligting (bv. verskillende plantkenmerke), op grond waarvan die ekspertstelsel dan die plant identifiseer en 'n unieke antwoord (soos die plantnaam) verskaf. Met die truwaartse metode verskaf dic gebruiker dic finalc antwoord (bv. dic plantnaam), en die ekspertstelsel verskaf dan dic individucle brokkies inligting (bv. die verskillende kenmerke van dié spesifieke plant)

\section{EKSPERTSTELSEL-ONTWIKKELING}

Elke ekspertstelsel moet doelgemaak ontwikkel word vir die spesificke tocpassing daarvan. Dit is normaalweg nic dic mocitc en koste werd om 'n ckspertstelsel vir eenmalige gebruik tc ontwikkel nic. Suksesvolle ontwikkeling van 'n ekspertstelsel hang af van:

- beskikbaarheid van geskikte en toepaslike inligting;

- die korrekte interpretasic van die beskikbare inligting; 
- korrekte vertaling en voorstelling van dic inligting in rekenaarformaat;

- 'n ekstensiewe lys van relevante vrae wat oor die betrokke onderwerp gevra kan word;

- al die moontlike antwoorde vir elk van dic vrac;

- die groepering en rangskikking van die vrae ten cinde op 'n sistematiese wyse sekere groepe van moontlikhede te elinineer na elke vraag en antwoord;

- die afleidings wat gemaak sal kan word op grond van die verskillende brokkies inligting wat verskaf word; en

- beskikbaarheid van 'n kundige rekenaarprogranmecrder, geskikte apparatuur en programmatuur.

Dit is belangrik om te onthou dat geen proses gerekenariseer of geoutomatiseer kan word tensy die proses eers behoorlik verstaan word nie. Rekenarisering gebruik bloot dic geheue, herhaalbaarlheid, en vinnige berekeningstempo van 'n rekenaar, ten cinde die vermoëns van die menslike brein aan te vul. $\Lambda \mathrm{s}$ die rekenaar op 'n onsinnige wyse geprogrammecr word, of as onsinnige data darin gestoor word, of as onsinnige insette daaraan gegee word, sal onsinnige uitsette verkry word.

\section{EKSPERTSTELSEL, VIR DIE IDENTIFIKASIE VAN LITHOPS}

\subsection{Tipiese identifikasiekriteria}

Die tipiese vrae (met moontlike antwoorde) wat deur'n ekspertstelsel vir die identifikasic van Lithops aan 'n gebruiker gestel kan word, is:

1. Wat is die kleur van die blomme (gecl / wit / onbekend [plant blom nie tans nic])?

2. Hoe lyk die blomme se kroonblare (groot / klein / onbekend [plant blom nic tans nic])?

3. Hoc lyk die blom (lank / kort / onbekend [plant blom nic tans nie])?

4. Hoc lyk die profiel [sy-aansig] van die plant (plat bokant / effens bolronde bokant / bolronde bokant / V-vormig)? Verwys na figuur 3.

5. Hoc lyk dic bo-aansig van dic plant (rond / ellipties / agtvormig / niervormig / oopgesper ellipties)? Verwys na figuur 4.

6. Hoc lyk die tekstuur van die bo-aansig (glad / effens grof / grof)?

7. Wat is die voorkoms van die blaargesig (deurskynend / niedcurskynend)?
8. Hoe lyk die spikkelpatroon van 'n lengtesnit deur dic plant (slegs bokant / slegs buiterande / bokant en buiterande / oral / onbekend [hierdie is 'n destruktiewe toets, en kan nie altyd gedoen word nic])?

9. Hoe lyk die spikkelpatroon van die bo-aansig (baie en oral/ min en oral/slegs op omtrek / baic aan omtrek en min verder / slegs binnerande)? Verwys na figuur 5 .

10. Is daar enige strepe en kolle op die bo-aansig ( $\mathrm{ja} / \mathrm{nec}$ )?

11. Indien daar strepe en kolle op die bo-aansig is, is dit (vlak/ diep / verhewe)?

12. Wat is dic oorheersende gesigkleur (ligte groen / olyfgroen / donker groen / rooi / pers / ligte grys / donker grys / ander)?

13. Hoc lyk dic sy-aansig van dic saadhuisies (rond/ rond met plat bo- en onderkant / rond met gepunte bokant en plat onderkant/ onbekend [saadhuisies nic tans beskikbaar nic])?

14. Hoc lyk die bo-aansig van die saadhuisies (rond / vyfkantig / seskantig / onbekend [saadhuisies nic tans beskikbaar nic])?

Alhoewel bostaande lys van vrae dic belangrikste kenmerke van Lithops dek, kan die lys sckerlik nog uitgebrei word. Om egter net hierdic vrae in 'n stel besluitnemingsreëls saam te vat, en om die inligting wat op grond van dic vrae versamel word, te verwerk, is reeds 'n enorme taak. 'n Eenvoudige samevoeging van al die moontlike antwoorde wat hicrbo gelys word, lewer sowat 35 miljoen moontlike kombinasies. (Hiermee word geensins geïmpliseer dat daar 35 miljoen verskillende Lithops is nie, maar bloot dat dit die getal antwoord-kombinasies is waardeur die ekspertstelsel sal moet sif.) On sake verder te bemocilik, is daar nog intraspesificke variasies ook. So beskryf Colc' soms 'n plant as: "Windows' usually \pm occluded, occasionally \pm completely open, sometimes reduced to very narrow channels and miniwindows ...."

\section{$5.2 \quad$ Implementering}

As 'n wegspringpunt is daar besluit om 'n ekspertstelsel te ontwikkel rondom slegs die volgende kenmerke: ${ }^{1,8}$

1. Profiel

a. Vorm (plat bokant / bolronde bokant / V-vormig met plat bokant / V-vormig met bolronde bokant).

b. Skeurdiepte tussen dic twee blare ( $1-2 \mathrm{~mm} / 3-7 \mathrm{~mm} / 8-12$ $\mathrm{mm} />12 \mathrm{~mm}$ ).

2. Gesig

a. Bo-aansig (rond / ellipties / agt-vormig / nicrvormig / oopgesper ellipties).

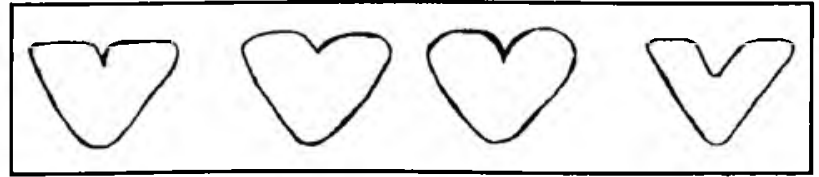

Figuur 3: Tipiese Lithops-profiele.

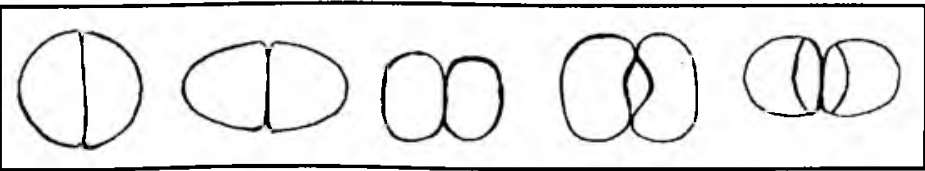

Figuur 4: Tipiese Lithops-bo-aansigte.

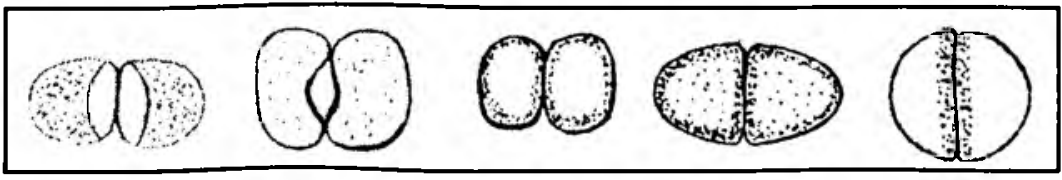

Figuur 5: Tipiese spikkelpatrone van Lithops-bo-aansigte. 
b. Gelykheid van blaargesig (gelyk / tussenin / ongelyk).

c. Tekstuur (glad/effens grof/grof).

3. Grenslyne op buiterand van bo-aansig

a. Duidelikheid (duidelik / onduidelik).

b. Wydte (smal / breed).

c. Rec̈lmatigheid (rec̈lmatig / onreëlmatig).

d. Skiereilande (ja/nee).

4. Vensters / deurskynende dele op gesig (groot / gedecltclik oop / afwesig).

5. Strepies / kanale op gesig
a. Wydte (smal / breed).
b. Deurskynendheid (deurskynend / ondeurskynend).
c. Diepte (ingesink/ gelyk met gesig).

Die aantal moontlikhede wat uit bostaande opsies voortspruit, is steeds baic (in die orde van tweehonderd en tagtig duisend), maar dit is aansienlik minder as die 35 miljoen soos voorheen bespreek. Die prys wat vir hicrdie verlaagde kompleksiteit betaal word, is 'n verlies aan identifikasie-akkuraatheid. In plaas van 'n unicke antwoord op elke navraag, gee die ekspertstelsel nou 'n aantal moontlike antwoorde, wat dan self verder deur die gebruiker verfyn moet word. Die doelwit was dat hierdie aanvanklike stelsel nie meer as vyf moontlike antwoorde op 'n navraag moet verskaf nic. Die rasionaal was dat dit beter is om aanvanklik ' $n$ eenvoudiger en vinniger ekspertstelsel te hê, wat wel werk; en dat dit beter is om uit vyf moontlike antwoorde te moet kies wanneer 'n spesifieke Lithops geîdentifiseer moet word, as wat dit is om uit meer as 110 moontlikhede te moct kies.

Datatabelle - soos bv. in tabel 1 getoon - is vir 110 soorte Lithops saamgestel op grond van beskikbare inligting, en dit is in rekenaargeheue gestoor.

\subsection{Uitsette}

Dic truwaartse benadering is maklik, deurdat die gebruiker 'n spesifieke Lithops se naam verskaf, en dic ekspertstelsel dan al die kenmerke van die spesifieke plant, soos gestoor in die databasis, aan die gebruiker vertoon. Die voorwaartse benadering is die moeiliker cen, omdat die doelwit daarmee is om op 'n sistematiese wyse die aantal moontlikhede te verminder, en om op grond van gebruikerinsette 'n spesifieke plant te identifiseer. Plantkenmerke wat nie een-eenduidig gekarakteriseer kan word nie, maak die elimineringsproses vir die ekspertstelsel baie moeilik. Hoe meer kenmerke in die databasis ingesluit kan word, hoe minder sensitief is die stelsel vir onsekere, en selfs verkeerde, antwoorde.

Weens die verminderde aantal identifikasiekriteria gee die ekspertstelsel tans geen antwoord in sowat $40 \%$ van alle navrae nie. In hierdie gevalle kan die stelsel nie die gegewe insette korrelleer met die gestoorde data nie. In sowat $55 \%$ van die gevalle gee die ekspertstelsel vyf of minder moontlikhede waaruit die gebruiker dan moet kies; en in sowat $5 \%$ van die gevalle word meer as vyf moontlike antwoorde gegee. Alhoewel die stelselwerking tans nog glad nic as baie goed bestempel kan word nic, is dit reeds 'n goeie begin. Die stelselwerking kan verbeter word deur meer identifikasickriteria te gebruik, maar net in ruil vir groter kompleksiteit en stadiger reaksietyd. Met voortdurende verbeteringe in rekenaartegnologic is hierdic nadele egter vinnig besig om onbeduidend te raak.

\section{SLOTOPMERKINGS}

Hierdic projek is begin as 'n elektriese- en elektronieseingenicurstudent se finalejaar-projekondersock; ${ }^{8} \mathrm{en}$ is met baic beperkte hulpbronne aangepak. 'n Werkende prototipe van dic ekspertstelsel is ontwikkel, wat nog uitgebrei en verfyn moet word. Nieteenstaande die gebreke van dic huidige stelsel is dit recds 'n nuttige instrument vir identifikasic van Lithops. 'n Moontlike tockomstige uitbreiding van die stelsel kan wees om masjienvisic te gebruik om dic rekenaar self te laat besluit wat is die kenmerke van die plant wat geïdentifisecr moet word. Voor dit egter aangepak word, moet die huidige ekspertstelsel nog eers verbeter word. Die resultate wat wel behaal word met 'n relatief eenvoudige ekspertstelsel toon die groot potensiaal wat hierdic tipe tegnologie het.

\section{ERKENNING}

Dic outeur spreek graag dank uit teenoor mnr. J.D. Bredenkamp wat die prototipe-databasis ${ }^{4}$ wat in hicrdic artikel vermeld word, ontwikkel het; en tecnoor mnr. Jacob van Pareen, wat vir jare reeds sy grondige kennis en entocsiasme oor Lithops vryelik deel.

\section{LITERATUURVERWYSINGS}

1. Colc, D.T. (1988). Lithops - Flowering Stones (Acorn Books, Randburg).

2. Dallwitz, M.J. (1992). A Comparison of Matrix-Based Taxonomic Idcntification Systcms with Rulc-Based Systems, Proceedings of IFAC Workshop on Expert Systems in Agriculture, 21 5-218 (International Academic Publishers, Bcijing).

3. http://biodiversity.uno.cdu/dclta/www/idprogs.htm

4. Bcynon-Davics, P. (1991). Expert Database Systems - A Gentle Introduction (McGraw-Hill, London).

5. Lucas, P. (1991). Principles of Expert Systems (Addison-Wcslcy, Wokingham).

6. Forsyth, R. (1989). Expert Systems - Principles and Case Studies (Chapman \& Hall, London).

7. Nebendahl, D. (1988). Expert Systems - Introduction to the Technology and Applications (Wilcy, Ncw York).

8. Bredenkamp, J.D. (1995). 'n Rekenaar-gebaseerde Klassifikasiestelsel vir Lithops. B.Ing. (Elcktrics en Elcktronies)-skripsic (Randsc Afrikaansc Universitcit, Johannesburg).

Tabel 1 Voorbeeld van data wat vir elke soort Lithops gestoor word

\begin{tabular}{|c|c|c|c|c|c|}
\hline Identifikasie-nommer & Naam & Profielvorm & Skeurdiepte & Gesigvorm & ..... \\
\hline 1 & $\begin{array}{l}\text { L. aucampiae } \\
\text { Subsp. aucampiae } \\
\text { var. aucampiae }\end{array}$ & Plat bokant & $3-7 \mathrm{~mm}$ & Niervormig & ..... \\
\hline 2 & $\begin{array}{l}\text { L. aucampiae } \\
\text { Subsp. aucampiae } \\
\text { var. aucampiae } \\
\text { cv. Betty's Beryl }\end{array}$ & Plat bokant & $3-7 \mathrm{~mm}$ & Niervormig & ..... \\
\hline 3 & $\ldots .$. & ...... & ..... & $\ldots .$. & ..... \\
\hline ...... & $\ldots \ldots$ & $\ldots .$. & ..... & $\ldots .$. & ..... \\
\hline 110 & L. werneri & Bolronde bokant & $4-8 \mathrm{~mm}$ & Agt-vormig & ..... \\
\hline
\end{tabular}

